\title{
El régimen de notificaciones: la dirección electrónica vial (DEV) y el tablón edictal de sanciones de tráfico (TESTA)
}

\author{
Eduardo Gamero Casado \\ Catedrático de Derecho Administrativo \\ Universidad Pablo de Olavide, de Sevilla \\ gamero@upo.es
}

\begin{abstract}
Resumen
La modificación de la Ley de tráfico promueve la implantación de soluciones de administración electrónica como mecanismo para la mejora de la eficacia en la tramitación de los procedimientos sancionadores en materia de tráfico. En este artículo se expone el nuevo régimen de notificaciones administrativas derivado de la reforma, en el que se contempla la adhesión forzosa a sistemas de notificación electrónica por parte de las personas jurídicas titulares de vehículos. La polémica que podría desatarse como consecuencia de esta opción legislativa-perfectamente constitucional por otra parte-, se neutraliza por la posibilidad que se reconoce a las personas interesadas de modificar el canal de comunicación y pasar al soporte papel una vez practicada la primera notificación en la DEV.
\end{abstract}

Palabras clave

Tráfico, procedimiento sancionador, administración electrónica, notificaciones.

\section{The notification system: viale-mail address (DEV) and the board edictal of traffic sanctions (TESTA)}

\begin{abstract}
The amendment of the Spanish Transit Act promotes the implantation of eGovernment solutions as a mechanism for the improvement of the efficiency in the handing of the penalti procedures. This paper reflects the new system of personal notices derived from the reform, which provides an electronic system of notification, which is mandatory for all the juristic persons that hold vehicles. This situations is perfectly constitutional, but can be quite polemic. Anyway, the Law gives citizens the opportunity to change the channel of communication and go to the paper-postal notice-once practiced the first electronic personal notice.
\end{abstract}

Key words

Transit rules, penalty procedure, eGovernment, personal notices. 


\section{INTRODUCCIÓN: ¿POR QUÉ UN SISTEMA ESPECÍFICO DE NOTIFICACIONES ELECTRÓNICAS EN MATERIA DE TRÁFICO?}

La notificación es un trámite esencial en la gestión administrativa, pues de su práctica depende la eficacia de los actos que afectan a derechos e intereses legítimos de la ciudadanía -art. 58.1 LRJPAC-. En materia sancionadora, el rigor formal de la notificación se acrecienta en razón de la afección a derechos constitucionales, como se expone en otros lugares de este número al abordar el estudio del procedimiento administrativo sancionador. Se comprende entonces perfectamente que la práctica de la notificación constituya una de las piedras angulares sobre las que se asienta la tramitación de los procedimientos sancionadores, tanto en materia de tráfico como en otros ámbitos sectoriales.

Frente a este carácter nuclear de las notificaciones administrativas, la realidad es que en el último cuarto de siglo su práctica viene representando un verdadero tormento para los tramitadores de los procedimientos. Esto obedece, entre otros factores, a la transformación antropológica que ha experimentado progresivamente la familia en las últimas décadas: la sociedad actual ha variado radicalmente sus hábitos domésticos, dificultándose de manera extraordinaria la entrega de notificaciones postales, al encontrarse los domicilios desocupados la mayor parte del tiempo.

En materia de tráfico, los obstáculos a la práctica de la notificación se acrecientan por la falta de actualización de los domicilios de los presuntos infractores. Conforme a las reglas generales de aplicación, en el caso de no poder identificar al conductor y entregarle la denuncia in situ, se procede al envío del acuerdo de incoación del procedimiento a la dirección del titular que figura en el permiso de circulación del vehículo. Es muy frecuente que esa dirección no se encuentre actualizada, por lo que resulta preciso seguir toda la burocrática tramitación que impone el art. 59 LRJPAC (segundo intento en el plazo de tres días y a distinta hora, notificación edictal, publicación en diario oficial), en la que aumenta la probabilidad de incurrir en algún vicio de forma que después dé al traste con todo lo actuado. Por otra parte, estas gestiones demoran ampliamente la eficacia de la resolución sancionadora (que no se alcanza hasta que el acto es debidamente notificado), y ello a pesar de que los trámites concebidos para lograr la notificación son generalmente un mero ritual que no llega a alcanzar su propósito (que el contenido del acto llegue a conocimiento de su destinatario): por un lado, si el domicilio no se encuentra actualizado, el segundo intento de notificación es perfectamente superfluo; y por otro, es indudable que los ciudadanos no dedican precisamente la mañana a acercarse a su Ayuntamiento para ver el tablón de edictos a fin de comprobar si se les notifica algún acto administrativo, y tampoco a leer minuciosamente los diarios oficiales con esa misma intención. A resultas de todo ello, y como atinadamente se expresa en la Exposición de Motivos de la Ley 18/2009, de 23 de noviembre, por las que se modifica el texto articulado de la Ley sobre tráfico, circulación de vehículos a motor y seguridad vial (TALT): "Las notifica-

34 la notificación ha sido practicada. Sin embargo, no ofrecen garantía materialalguna 
ciudadano de que tenga siempre conocimiento de los procedimientos que contra él se dirigen".

En efecto, no es raro que la primera noticia del procedimiento que tenga el presunto infractor resida en la iniciación de la vía de apremio, que suele confiarse a la Agencia Tributaria, en cuyas bases de datos los domicilios sí se encuentran actualizados. La Exposición de Motivos de la Ley 18/2009, lo reconoce abiertamente al declarar que "las deficiencias derivadas del sistema actual de notificaciones en el procedimiento, provocan al conductor una clara vulneración del derecho a conocer el estado de la tramitación de los procedimientos en los que está implicado, derecho que le reconoce el artículo 35.a de la Ley 30/1992, de 26 de noviembre, de Régimen Jurídico de las Administraciones Públicas y del Procedimiento Administrativo Común".

La situación no puede ser más desafortunada para todos: los ciudadanos se ven privados de la posibilidad de ejercer su defensa a lo largo del procedimiento, al que se le despoja del carácter contradictorio por razones absolutamente accidentales; y la Administración sancionadora complica inútilmente su gestión ordinaria, incrementando la dedicación de recursos humanos y materiales, exponiéndose a incurrir en mayores porcentajes de infracciones formales, y viendo demorarse sucesivamente la eficacia de la resolución sancionadora.

Esta desaconsejable situación no es específica de las notificaciones en materia de tráfico, sino extrapolable a amplios sectores de la gestión administrativa. Evidencia la necesidad de acometer reformas que afronten el problema y le busquen remedio. Un buen instrumento para lograrlo es mediante la aplicación de las tecnologías de la información y la comunicación al procedimiento administrativo, cuya utilidad no ha pasado desapercibida al legislador estatal básico, materializándola en la Ley 11/2007, de 22 de junio, de acceso electrónico de los ciudadanos a los servicios públicos (en lo sucesivo, LAE), convencionalmente conocida como Ley de administración electrónica: una magnífica disposición, repleta de aciertos, que ha situado a España en la vanguardia mundial de la ordenación jurídico-positiva de la materia'. Sin embargo, en materia de comunicaciones y notificaciones telemáticas, el texto de la Ley de administración electrónica no resuelve adecuadamente diferentes aspectos concernidos por la práctica de la notificación.

En efecto, las notificaciones telemáticas fueron uno de los primeros aspectos de la administración electrónica que recibieron atención por parte del legislador estatal básico: mediante la Ley 24/2001, de medidas fiscales, administrativas, y del orden social, que modificó el art. 59 de la Ley 30/1992 a fin de regular las notificaciones electrónicas². En

1 Como coincide en afirmar unánimemente la doctrina; véanse los comentarios que al efecto realizan los diferentes autores en Gamero y Valero 2009; Valero, 2007; Martínez, 2009; y Davara, 2010.

2 Sobre el régimen de las notificaciones electrónicas previo a la Ley 11/2007 pueden verse especialmente Gamero, 2005; y Gamero, 2002; así como Valero (edición de 2004); Martín Delgado, 2005: 171 SS.; Bauzá, 2002: 176 ss.; y Dávila, 2001: 48 ss. 
desarrollo de sus previsiones se dictó el RD 209/2003, de 21 de febrero, por el que se regulan los registros y las notificaciones telemáticas, así como la utilización de medios telemáticos para la sustitución de la aportación de certificados por los ciudadanos; si bien su ámbito de aplicación se contrae a la Administración del Estado. Y mediante un desarrollo normativo de segundo grado, se reguló a su vez la materia en la Orden PRE/1551/2003, de 10 de junio, por la que se desarrolla la disposición final primera del Real Decreto 209/2003.

El producto final de todo ello desde el punto de vista práctico fue la puesta en marcha de un Servicio de Notificaciones Telemáticas Seguras (SNTS) por parte del Ministerio de Administraciones Públicas, confiándose su prestación material a Correos y Telégrafos mediante un convenio suscrito por ambas partes el 22 de octubre de 2003. El servicio arrancó de manera efectiva en 2004, y según los indicadores hechos públicos por el Ministerio en noviembre de 2008 (últimos datos disponibles), sus principales magnitudes (globales para los cuatro años de funcionamiento) son las siguientes: 50.000 direcciones electrónicas creadas, 14 organismos emisores integrados en el servicio, y 1.000.000 de notificaciones practicadas. Tales estadísticas de uso son francamente decepcionantes, y no resisten la menor comparación con otros servicios de administración electrónica articulados por la Administración del Estado: por ejemplo, la presentación telemática del IRPF ha sido realizada en 2009 por 6.913.368 contribuyentes, un 22,9\% más que en 2008; sobre el total de declaraciones, las presentadas por Internet suponen un $35 \%$. Ya no vale decir, por otra parte, que la Administración Tributaria no puede ofrecerse como parámetro de contraste debido a su ya larga tradición en la materia: en otros ámbitos sectoriales, como afiliación de trabajadores a la Seguridad Social, o la solicitud de cita médica por Internet, ofrecen cifras igualmente satisfactorias. EI SNTS constituye un rotundo fracaso, lo cual no solo es reprochable por el gasto que ha supuesto su entrada en funcionamiento, sino que además supone una clara frustración de las expectativas de los ciudadanos, pues a la vista queda que, cuando los servicios de administración electrónica se encuentran debidamente configurados desde el punto de vista técnico y jurídico, los utilizan masivamente dado que les facilitan mucho las cosas. A mi juicio, son fundamentalmente los siguientes motivos los que han conducido a esta decepcionante situación:

- La complejidad que entraña la elección del medio por parte del ciudadano, que exige dos trámites sucesivos para manifestar su consentimiento a la notificación electrónica: la indicación del medio electrónico como preferente, y la suscripción a concretos procedimientos.

- El hecho de que tal elección debe hacerse con cada Administración públi$c a$, obligando al ciudadano a realizar el trámite infinidad de veces y con interlocutores diferentes (con cada Administración que se relacione, y en cada concreto procedimiento al que se suscriba). Es muy llamativo que no exista un servicio cen36 nes públicas. 
- La deficiente regulación de la posibilidad de remitir directamente notificaciones electrónicas a los ciudadanos en procedimientos iniciados de oficio.

— Las limitaciones de los propios servicios de notificación, que ofrecen utilidades muy reducidas.

- El escaso período de permanencia de la notificación (10 días) en el buzón electrónico del ciudadano, que le puede llevar a desconfiar del sistema, pues le obliga a estar continuamente alerta revisando si le han llegado notificaciones a los diferentes sistemas de notificación a los que esté suscrito.

- El hecho de que, cuando el destinatario no descargue la notificación una vez transcurrido ese plazo, se entenderá rechazada (no infructuosa), colocándole en una posición muy desfavorable frente a los ciudadanos que son notificados por el medio postal tradicional.

Algunos -no todos- de estos defectos han pretendido y logrado corregirse por el recientemente dictado Real Decreto 1671/2009, de 6 de noviembre, por el que se desarrolla parcialmente la Ley 11/2007 (en lo sucesivo, RDLAE). Pero es imposible afrontarlos todos en una disposición de rango meramente reglamentario, que modifique o excepcione la aplicación de la Ley de administración electrónica.

Cabe pensar que todo este cúmulo de circunstancias y razones hallevado a las autoridades responsables del tráfico a promover otro tipo de soluciones que remedien, o al menos aminoren, los problemas que viene presentando la notificación administrativa en los procedimientos sancionadores. $Y$ en ese contexto se encuadra la Ley $18 / 2009$, que aplica las tecnologías de la información y la comunicación a la notificación de las sanciones de tráfico, aportando innovaciones jurídicas que pretenden afrontar algunas de las carencias del Derecho preexistente, en particular, imponiendo el canal electrónico como medio obligatorio de notificación en ciertos casos. Al objeto de lograr este propósito se excepciona la aplicación del resto de disposiciones que confluyen en la ordenación jurídica de la materia. Por ello, como presupuesto del resto del análisis, es preciso analizar en primer lugar la novedosa y complicada ordenación de las fuentes del Derecho a que conduce esta Ley.

\section{EL SISTEMA NORMATIVO DE LAS NOTIFICACIONES ELECTRÓNICAS DE TRÁFICO}

Para analizar el régimen jurídico de las notificaciones electrónicas de tráfico es preciso concretar en primer término el marco normativo de aplicación, identificando las disposiciones cuyo contenido material confluye en la ordenación de este objeto y estableciendo la prelación que debe seguirse en orden a su aplicación, lo que determinará una sucesión de grupos normativos consecutivamente supletorios unos de otros, siendo todos ellos de consideración necesaria en la concreción del régimen material aplicable. 
En primer lugar, se notará que la Disposición final primera de la Ley 18/2009 introduce una nueva Disposición adicional octava bis en la Ley 30/1992, que declara de aplicación preferente al procedimiento sancionador en materia de tráfico las previsiones que se contienen en su legislación específica ${ }^{3}$. Está lejos de mi intención profundizar en el sentido de esta excepción en cuanto pueda suponer una quiebra de la concepción del Derecho estatal común que tenemos asentada en materia de procedimiento administrativo, toda vez que ese análisis desborda por completo el propósito y el ámbito de este trabajo. Pero no puede dejar de notarse que esta operación normativa supone desplazar el contenido de la Ley 30/1992, y conduce la aplicación preferente del Texto articulado de la Ley de tráfico, en todo lo referente al procedimiento sancionador. Se trata, por tanto, de la primera norma que debe ser tomada en consideración en punto a determinar el régimen jurídico de las notificaciones de tráfico: el propio Texto Articulado de la Ley de tráfico, por tratarse de una ley especial y encontrarse la relación entre ambas normas presidida por el principio de especialidad.

Como resulta obvio, las determinaciones de la Ley de tráfico en materia de notificaciones constituyen unos contenidos fragmentarios, en todo punto insuficientes para regular el conjunto de trámites y requisitos que rodean la práctica de la notificación. Se trata entonces de saber cuál es la siguiente norma aplicable en el sistema de fuentes. En este sentido, se advertirá que existe otra Ley estatal común, dictada en virtud del mismo título competencial que la 30/1992, pero específica en materia de administración electrónica, y en cuya concurrencia material no repara la Ley 18/2009: la ya citada Ley de administración electrónica. En mi opinión, precisamente por la relación de especialidad/generalidad existente entre ambas ${ }^{4}$, la Ley 11/2007 es de aplicación prevalente sobre la Ley 30/1992 en todo lo que respecta a las comunicaciones y notificaciones electrónicas.

Es más, esta segunda posición en la prelación de fuentes corresponde realmente a todo el grupo normativo encabezado por la Ley de administración electrónica: esto es, la Ley 11/2007 y sus disposiciones de desarrollo; en particular, el Real Decreto 1671/2009, de desarrollo parcial de dicha Ley, en el que se contiene una amplia regulación de las notificaciones administrativas, coherente con la propia Ley de tráfico, y complementaria de sus contenidos, por cuanto que añade algunas precisiones que podrían ser útiles llegado el caso.

3 El texto de la nueva Disposición adicional 8 bis de la Ley 30/1992 es el siguiente" Los procedimientos administrativos para la imposición de sanciones por infracciones en materia de tráfico, circulación de vehículos a motor y seguridad vial, se regirán por lo dispuesto en su legislación específica y, supletoriamente, por lo dispuesto en esta Ley".

4 Sobre la construcción dogmática de esa relación debe consultarse Bobbio, 1960: 69 ss.; DíezPicazo, $1990: 68$ ss. y 344 y ss.; Mondugno, 1978: 513 ss.; y Gavazzi, 1959: 81 ss. Otras ampliaciones sobre las relaciones de especialidad y generalidad en materia de administración electrónica pueden verse en Gamero, 2009: 97 ss. 
Como cierre del sistema se posiciona pues la Ley 30/1992, que es Ley general respecto de la Ley 11/2007, y esta última lo es a su vez respecto de la Ley de tráfico, en una sucesión de relaciones de especialidad-generalidad que ha venido a ser explicada en la teoría general del Derecho acudiendo a la imagen metafórica de los círculos concéntricos 5 . En el lugar oportuno comprobaremos la oportunidad de haber sentado estas pautas en la prelación de fuentes de aplicación.

\section{LOS MEDIOS ELECTRÓNICOS DE NOTIFICACIÓN EN MATERIA DE TRÁFICO}

\section{La Dirección Electrónica Vial (DEV)}

\section{A) Noción y características}

Ningún precepto de la Ley de tráfico define lo que es la Dirección Electrónica Vial (en adelante, DEV). Hemos de entender que se trata de un sistema de notificación electrónica específico en materia de tráfico. Por notificación electrónica entendemos, a su vez, un medio telemático por el que se da traslado del contenido de un acto administrativo a su destinatario ${ }^{6}$. El Texto articulado de la Ley de tráfico no concreta las características del servicio de notificación que se pondrá en marcha, sino tan sólo sus requisitos generales. El único descriptor de las características del servicio de notificación mediante el que se conformará la DEV es el art. 77.2 TALT, cuya rúbrica se ciñe a la notificación de las denuncias, aunque en realidad su contenido material es aplicable al conjunto del sistema de notificación, y por consiguiente, a cualquier trámite que se practique por ese medio. Según su texto, "El sistema de notificación en la Dirección Electrónica Vial permitirá acreditar la fecha y hora en que se produzca la puesta a disposición del denunciado del acto objeto de notificación, así como el acceso a su contenido".

El catálogo de exigencias es tan reducido que, en orden a la puesta en marcha de un servicio de notificaciones electrónicas, se puede traducir en una extraordinaria variedad de sistemas de notificación?. En este sentido, el art. 28.2 de la Ley de admi-

5 Pues, en efecto, la relación generalidad/especialidad es predicable de pares normativos, de forma que la ley $L 1$, especial respecto a la ley $L 2$, puede al propio tiempo ser general respecto a la ley $L 3$; idea en la que insiste especialmente Mondugno, 1978: 514, expresándola con la imagen metafórica de los círculos concéntricos. V., asimismo, Díez-Picazo, 1990: 345.

6 La única particularidad que entraña la notificación electrónica es por consiguiente el medio por el que se practica: la comunicación entre equipos electrónicos (denominada técnicamente telemática); por tanto, estamos en este punto a la definición genérica de notificación administrativa, y son de necesaria aplicación a las notificaciones electrónicas todos los requisitos de contenido establecidos en el art. 58 LRJPAC. Véanse Gamero, 2001: 76 ss.; Gamero, 2005: 106 ss.; Martín Delgado, 2005: 183; Martín Delgado, 2009: 57; Martínez, 2009: 538.

7 Lo cual es coherente con la propia amplitud e indeterminación con la que se regulan los medios de notificación en el art. 59 LRJPAC, que no contiene un catálogo cerrado de medios de notificación, sino que establece tan sólo los requisitos generales -fundamentalmente de constancia- que debe reunir el medio 
nistración electrónica, cuyo texto es prácticamente idéntico al trascrito ${ }^{8}$, también muestra una gran flexibilidad en este punto, estableciendo tan sólo los requisitos generales del sistema de notificación, lo cual puede traducirse realmente en una amplia variedad de herramientas o aplicaciones informáticas que apliquen soluciones completamente distintas 9 ; igualmente se refleja, por otra parte, en el RD 1671/2009, que relaciona una diversidad de "formas" de notificación ${ }^{10}$, en un catálogo que además es abierto y no exhaustivo" ${ }^{11}$. Esta flexibilidad es acertada, por cuanto que la tecnología avanza a gran velocidad y no conviene congelar en una norma con rango de ley un concreto sistema o forma de notificación, sino admitir un amplio grado de adaptación al progreso tecnológico que permita implantar soluciones aptas para satisfacer las exigencias legales sea cual sea el momento en que se consigan.

Debemos reparar en que el art. 77.2 TALT exige que quede constancia de la transmisión, pero no que sea fehaciente, por lo que la prestación de servicios de notificación no queda reservada al sector público ni a operadores cualificados. En el universo digital existen muy diferentes tecnologías con las que acreditar una transmisión; ahora bien, a efectos de constancia, y con el fin de robustecer el valor probatorio del instrumento electrónico mediante el que se acredite la realización del trámite, es esencial la concurrencia de un tercero, pues si los elementos de control del sistema quedan completamente bajo la órbita del órgano notificante, ello privaría a los instrumentos de constancia de la necesaria neutralidad ${ }^{12}$.

empleado. El art. 28 LAE, y ahora el 77.2 TALT, no hacen sino trasladar esa misma generalidad al ámbito de las notificaciones electrónicas, reconociendo la validez de todos los sistemas de notificación electrónica que satisfagan una serie de exigencias mínimas, específicas para los medios electrónicos de notificación.

$8 \quad$ El art. 28.2 LAE dispone: "El sistema de notificación permitirá acreditar la fecha y hora en que se produzca la puesta a disposición del interesado del acto objeto de notificación, así como la de acceso a su contenido, momento a partir del cual la notificación se entenderá practicada a todos los efectos legales".

9 Acerca de los requisitos que establece dicho artículo en relación con los sistemas de notificación electrónica, véanse Martín Delgado, 2009: 57 ss.; Valero, 2007: 154 ss.; Rego, 2009: 419 ss.; Martínez, 2009: 544 Ss.

10 A título de ejemplo, véanse los arts.38 ss. del Real Decreto 1671/2009, que ofrecen un panel (no exhaustivo) de formas de notificación acordes con las exigencias de la Ley. Como presupuesto de los preceptos citados (y a título indicativo de lo que pretendo decir), el art. 35.2 del mismo Real Decreto dispone: "La práctica de notificaciones por medios electrónicos podrá efectuarse, de alguna de las formas siguientes: decreto.

a) Mediante la dirección electrónica habilitada en la forma regulada en el artículo 38 de este real

b) Mediante sistemas de correo electrónico con acuse de recibo que deje constancia de la recepción en la forma regulada en el artículo 39 de este real decreto.

c) Mediante comparecencia electrónica en la sede en la forma regulada en el artículo 40 de este real decreto.

d) Otros medios de notificación electrónica que puedan establecerse, siempre que quede constancia de la recepción por el interesado en el plazo y en las condiciones que se establezcan en su regulación específica".

11 Sobre las formas o sistemas de notificación véase especialmente Martín Delgado, 2009: 82 ss.

12 Debe aclarase que hago referencia a instrumentos automáticos de constancia electrónica, y no a la intervención de personas que tienen conferida la condición de fedatarios públicos. Es en ese concreto sentido en el que se encuentra robustecido el instrumento electrónico de constancia de una comunicación $40 \quad \begin{aligned} & \text { electrónica cuando } \\ & \text { (ajeno a las partes). }\end{aligned}$ 
Esto no significa necesariamente que todo el sistema de notificación de la DEV tenga que confiarse necesariamente a un tercero (por ejemplo, a Correos y Telégrafos, que atesora una larga experiencia en la puesta en marcha de sistemas electrónicos de notificación, incluso con carácter fehaciente), pero sí al menos que la intervención del tercero de confianza tenga lugar durante el intercambio electrónico, esto es, al momento de producirse comunicaciones electrónicas: por ejemplo, para acreditar el momento de puesta a disposición de la notificación por parte de la Administración (que tiene relevantes efectos de cara a interrumpir los plazos de caducidad y prescripción), o de acceso al contenido de la notificación por parte del receptor. Este objetivo se logra, por ejemplo, cuando las comunicaciones se realizan previa acreditación de la identidad (uso de certificados electrónicos) por parte de los intervinientes; o al menos, cuando la comunicación electrónica registra la intervención puntual de un tercero de confianza que realiza alguna operación cualificada, como el time stamping o sello de fechas.

En este sentido, un aspecto clave del sistema es el mecanismo que se implante para asegurar la identificación electrónica del interesado. Se trata de un requisito que no deriva directamente de la Ley de tráfico, pero que a mi juicio resulta exigible al encontrarse previsto con carácter general en el art. 27.3 LAE, que dispone: "Las comunicaciones a través de medios electrónicos serán válidas siempre que exista constancia de la transmisión y recepción, de sus fechas, del contenido íntegro de las comunicaciones y se identifique fidedignamente al remitente y al destinatario de las mismas". La duda que se plantea es si el sistema de notificación exigirá una firma electrónica reconocida (por ejemplo, la que se aplica utilizando el certificado electrónico incluido en el DNIe, o el que suministra la FNMT), o bien se admitirán otros sistemas de identificación digital más flexibles. En este sentido, la Ley de administración electrónica admite un amplio repertorio de sistemas de firma electrónica $^{13}$, que pueden consistir en "claves concertadas en un registro previo, aportación de información conocida por ambas partes u otros sistemas no criptográficos" (art. 16.2 LAE).

Debido a que la creación de la DEV se produce automáticamente y con carácter necesario para todo un círculo de sujetos -como se verá un poco más tarde-, parece improbable que el sistema de comunicaciones asociado exija instrumentos de identificación de los que todavía carecen muchos ciudadanos. Por ello, cabe pensar que se implantará un medio de identificación electrónica basado en otras soluciones más simples y extendidas: quizá, con claves de acceso de conocimiento exclusivo entre las partes. Ahora bien, el sistema debe admitir en todo caso el acceso mediante el DNle, al tratarse de una obligación general dimanante del art. $14 \mathrm{LAE}^{14}$, y no sería extraño que admitiese también otros certificados electrónicos, como el de la FNMT.

13 Sobre los sistemas de firma electrónica admitidos por la Ley 11/2007, véanse principalmente Martín Delgado, 2009b: 341 ss.; Martínez, $2009: 565$ ss.; Palomar, 2007: 128 ss.; Barriuso, 2007: 129 ss.

14 Con arreglo a este precepto, “Las personas físicas podrán, en todo caso y con carácter universal, utilizar los sistemas de firma electrónica incorporados al Documento Nacional de Identidad en su rela- 
La Dirección General de Tráfico todavía no ha hecho públicas las características del servicio de notificación, pero sí se describen algunos pormenores en publicaciones de su órbita. Así ha llegado a saberse que la DGT tiene intención de enviar notificaciones por correo electrónico y mediante sms a los teléfonos móviles ${ }^{15}$. Únicamente sería posible esto último cuando existan terceros de confianza que puedan acreditar la realización de la comunicación y su contenido, servicio que ya prestan algunas empresas de servicios informáticos y de telecomunicación (en el caso del sms, siempre que el texto no exceda de 160 caracteres, lo cual los hace difícilmente aptos para contener el texto íntegro del acto, su pie de recursos, etc.), pero que resulta extraordinariamente caro. Pienso que, en realidad, el propósito de la DGT es implantar un servicio de notificaciones telemáticas análogo al que Correos y Telégrafos tiene en funcionamiento desde hace años (el Servicio de Notificaciones Telemáticas Seguras, o SNTS), y que en la actualidad debe reunir los requisitos de la dirección electrónica habilitada -art. 38 RDLAE-, el cual avisa a los destinatarios de las notificaciones que han recibido una notificación administrativa, enviándoles un mensaje de advertencia a su dirección de correo electrónico convencional, o mediante sms, a los solos efectos de que posteriormente accedan a la DEV para descargarse la notificación administrativa propiamente dicha. En este momento, los ciudadanos pueden suscribirse al SNTS para recibir notificaciones en materia de tráfico ${ }^{16}$.

\section{B) Asignación de la DEV. Obligatoriedad e intermodalidad del medio de notificación}

El modo de asignación de la DEV se regula en el nuevo art. 59 bis TALT, apdos. 3 a 6 , cuya confusa redacción conviene transcribir para proceder después a su comentario:

3. Sin perjuicio de lo dispuesto en el apartado primero, la Dirección General de Tráfico asignará además a todo titular de una autorización administrativa de conducción o de circulación de vehículo, y con carácter previo a su obtención, una Dirección Electrónica Vial (DEV). Esta dirección se asignará automáticamente a todas las autorizaciones de que disponga su titular en los Registros de Vehículos y de Conductores.

4. La asignación de la Dirección Electrónica Vial se realizará también al arrendatario a largo plazo que conste en el Registro de Vehículos, con carácter previo a su inclusión.

5. No obstante lo dispuesto en los apartados anteriores, si el titular de la autorización es una persona física sólo se le asignará una Dirección Electrónica

ción por medios electrónicos con las Administraciones Públicas. El régimen de utilización y efectos de dicho documento se regirá por su normativa reguladora".

15 Así se anuncia en la revista Tráfico y seguridad vial, n. ${ }^{\circ}$ 201-2010, accesible en http://www.dgt.es/ revista/num201/pdf/num201-2010-nuevaley.pdf (consulta realizada el 17 de mayo de 2010).

16 Desde el portal de la Dirección Genreal de Tráfico existe un enlace con el SNTS para facilitar el 42 alta en el servicio y la suscrpción al procedimiento. Por otra parte, en la misma publicación 
Vial cuando lo solicite voluntariamente. En este caso, todas las notificaciones se practicarán en esa Dirección Electrónica Vial conforme se establece en el artículo 77 , sin perjuicio del derecho que al interesado le reconoce el artículo 28.4 de la Ley 11/2007, de 22 de junio, de acceso electrónico de los ciudadanos a los servicios públicos.

6. En la Dirección Electrónica Vial además se practicarán los avisos e incidencias relacionados con las autorizaciones administrativas recogidas en esta Ley.

El régimen resultante de este orden de cosas es la asignación automática de una DEV a toda persona jurídica que obtenga una autorización de circulación de un vehículo (o que figure como arrendatario del mismo a largo plazo), DEV que además se aplicará como domicilio a efectos de notificaciones a todas las autorizaciones que se hayan emitido con anterioridad, convirtiéndose pues en el único lugar y medio de notificación de las actuaciones de tráfico. Por el contrario, para las personas físicas la obtención de la DEV es voluntaria, y se asignará previa solicitud del interesado. El momento a partir del cual la DGT comenzará a asignar la DEV a las personas jurídicas titulares de los vehículos es el mismo día de entrada en vigor del art. 59 bis ${ }^{17}$ : el 24 de noviembre de $2010^{18}$.

El diferente régimen de asignación de la DEV se corresponde asimismo con una sustancial diferencia en cuanto a la obligación de utilizar este medio de notificación. En principio, parece claro que se impone a las personas jurídicas el canal electrónico de notificación. En principio, los ciudadanos tienen reconocido el derecho a elegir el canal de comunicación que utilizarán con la Administración, dentro de los que se encuentren disponibles, pero este derecho encuentra su excepción en aquellos procedimientos que hayan establecido como obligatorio el canal electrónico -art. 27.1 LAE- ${ }^{19}$. Ello puede suceder de dos maneras: mediante normas con rango de ley cuando se trate de la ciudadanía en general-, o por disposiciones reglamentarias cuando se trate de grupos cualificados de sujetos -art. 27.6 LAE- ${ }^{20}$. El primer caso no supone innovación alguna, y es completamente armónico con nuestro sistema constitucional, en el que se reserva a la ley cualquier restricción sustantiva de la libertad "respecto de todos los actos del poder público que incidan de modo limitativo en la

17 Así lo establece la Disposición adicional $2^{a}$ de la Ley 18/2009. A partir de esa misma fecha las personas físicas podrán solicitar la asignación de una DEV.

18 La Disposición final $7^{\mathrm{a}}$ de la Ley $18 / 2009$ establece que este artículo entra en vigor al año de la publicación de la Ley en el Boletín Oficial del Estado.

19 Artículo que dispone: “Los ciudadanos podrán elegir en todo momento la manera de comunicarse con las Administraciones Públicas, sea o no por medios electrónicos, excepto en aquellos casos en los que de una norma con rango de Ley se establezca o infiera la utilización de un medio no electrónico".

20 Según este precepto: “Reglamentariamente, las Administraciones Públicas podrán establecer la obligatoriedad de comunicarse con ellas utilizando sólo medios electrónicos, cuando los interesados se correspondan con personas jurídicas o colectivos de personas físicas que por razón de su capacidad económica o técnica, dedicación profesional u otros motivos acreditados tengan garantizado el acceso y disponibilidad de los medios tecnológicos precisos". 
esfera jurídica o personal de los ciudadanos"21; de hecho, en materia de administración electrónica se había postulado la aplicación de esta misma regla, antes incluso de la Ley $11 / 2007^{22}$. En cuanto al segundo caso, debe descenderse al análisis del ámbito o sector concreto sobre el que se quiera imponer esta obligación para enjuiciar la concurrencia del presupuesto de hecho, operación que debe articularse necesariamente mediante un juicio de proporcionalidad ${ }^{23}$. A la vista de los datos estadísticos disponibles no es posible sostener que todas las personas jurídicas operativas en nuestro Derecho tengan garantizado el acceso y disponibilidad de los medios tecnológicos precisos ${ }^{24}$. Así pues, para disipar cualquier duda en cuanto a la suficiencia de rango, la imposición del canal electrónico se incorpora directamente en la Ley $18 / 2009$.

Ahora bien, es de notar que no se impone el canal obligatorio a todo lo largo del procedimiento sancionador, pues se salvaguarda el derecho del ciudadano a cambiar el canal de comunicación -lo que se conoce como intermodalidad-proclamado en el art. 28.4 LAE. Así, en el art. 74.3 f) TALT se advierte que la asignación de la DEV se hace “sin perjuicio de lo previsto en el artículo 28.4 de la Ley 11/2007, de 22 de junio"; y en el art. 59 bis. 5 TALT "todas las notificaciones se practicarán en esa Dirección Electrónica Vial conforme se establece en el artículo 77, sin perjuicio del derecho que al interesado le reconoce el artículo 28.4 de la Ley 11/2007, de 22 de junio, de acceso electrónico de los ciudadanos a los servicios públicos". El art. 28.4 LAE dispone: “Durante la tramitación del procedimiento el interesado podrá requerir al órgano correspondiente que las notificaciones sucesivas no se practiquen por medios electrónicos, utilizándose los demás medios admitidos en el artículo 59 de la Ley 30/1992, de Régimen Jurídico y del Procedimiento Administrativo Común, excepto en los casos previstos en el artículo 27.6 de la presente Ley".

Aunque esta conclusión resulta sorprendente, a la vista de estos preceptos solo cabe afirmar que la DEV es el medio necesario de notificación de la incoación del procedimiento sancionador, para todos cuantos la tengan asignada, voluntaria u obligatoriamente. Pero dichas personas, físicas o jurídicas, una vez iniciado el procedimiento y practicada la primera notificación en la DEV, podrán ejercer su derecho a solicitar la

21 Cfr. Santamaría, 1988: 781 ss. La aportación del autor sintetiza brillantemente la situación existente en España acerca del principio de reserva de ley, materia en la que pueden consultarse igualmente Baño, 1991: 199 ss.; Rebollo Puig, 1993: 97 ss.; y Beladíez, 2000: 333 ss.

22 Véanse Valero, 2007: 66 ss.; Gómez Puente, 2007: 123 ss.; y Cotino, 2004: 141 ss.

23 Como anticipara oportunamente Cotino, 2004: 143 Ss. Aunque sus reflexiones son anteriores a la Ley 11/2007, resultan plenamente oportunas en relación con el precepto en comentario. En la misma órbita se sitúan las posiciones de Bernadí, 2005: 230.

24 Según el estudio Tecnologías de la Información y las Comunicaciones en las PYMES y grandes empresas españolas 2010, elaborado por el Observatorio de Nuevas Tecnologías y de la Sociedad de la Información (ONTSI), y accesible en http://www.ontsi.red.es (visitada el 17 de mayo de 2010), el 96'2\% de las empresas (no el total) tiene acceso a Internet. A esto se le debe añadir que existen otras personas jurídicas que carecen de la condición de empresa (como asociaciones, fundaciones, etc.), y por consiguiente, sobre las que no existen estudios documentados acerca de su disponibilidad de tecnologías de información y comu-
nicación. 
modificación del canal de comunicación a fin de que las notificaciones sucesivas se practiquen en el domicilio postal y en soporte papel. Creo que este no era el propósito del legislador, quien probablemente pretendía que las comunicaciones con las personas jurídicas tuvieran lugar en todo caso mediante el canal electrónico. Como hemos comprobado un poco más arriba, era perfectamente posible hacerlo mediante una norma con rango de ley. Pero el contenido material que finalmente se ha dado a los preceptos no permite llegar a esa conclusión. Este orden de cosas puede arruinar el efecto pretendido por la reforma -un incremento en la eficacia de gestión de los procedimientos sancionadores-, por cuanto que, tras la notificación de la denuncia, necesariamente han de tener lugar otras: cuando menos, si se presentan alegaciones o se solicita práctica de pruebas, habrán de notificarse el trámite de audiencia y la resolución definitiva del procedimiento. El hecho de que estas notificaciones sucesivas deban practicarse en el domicilio postal y en soporte papel puede demorar la tramitación de los procedimientos en el mismo sentido que venía ocurriendo hasta ahora. Sin embargo, debe advertirse que, con arreglo a la Ley 11/2007, cuando se establece como obligatorio el canal electrónico, no se reconoce el derecho a la intermodalidad, estando obligados los interesados a mantener todas las comunicaciones en soporte electrónico ${ }^{25}$.

La generosidad del legislador al admitir el cambio de canal -y de soporte- resulta sorprendente. Parece ser una cláusula de prudencia, que promueve la confianza de los ciudadanos para que se animen a señalar como preferente el medio electrónico, sabiéndose salvaguardados con la posibilidad de renunciar a él si su empleo se revela insatisfactorio. Hasta aquí la explicación puede ser razonable. Pero no lo es que se proclame el derecho con la generosidad que se hace, sin reparar en las consecuencias que puede derivar sobre la gestión administrativa ordinaria ${ }^{26}$. En efecto, la norma parece proclamar el derecho con carácter absoluto, aun cuando pueda llegar a convertirse en un importante instrumento dilatorio en poder del ciudadano. Creo que la ponderación de intereses no ha sido adecuadamente aplicada por el legislador en este caso, y debía poderse condicionar por la Administración el cambio de canal cuando se deduzca un abuso del derecho. Pero, dado que la Ley no establece límites ni modulaciones a este derecho del ciudadano, no parece que la Administración pueda negarle el cambio de canal incluso cuando sea patente el uso instrumental del derecho como táctica dilatoria27.

25 Conforme al art. 28.4 LAE, "Durante la tramitación del procedimiento el interesado podrá requerir al órgano correspondiente que las notificaciones sucesivas no se practiquen por medios electrónicos, utilizándose los demás medios admitidos en el artículo 59 de la Ley 30/1992, de Régimen Jurídico y del Procedimiento Administrativo Común, excepto en los casos previstos en el artículo 27.6 de la presente Ley", es decir, cuando se haya establecido la obligatoriedad de relacionarse electrónicamente con las Administraciones públicas.

26 Que le han llevado a recibir severas críticas: vid. Rego, 2009: 400; Martínez, 2009: 542.

27 De hecho, alguna de las versiones del Proyecto de Real Decreto de desarrollo de la Ley 11/2007 establecía que "El órgano u organismo actuante podrá limitar sucesivos cambios en el medio elegido en la tramitación de un mismo procedimiento, en el caso de que se aprecie un uso abusivo del derecho", previsión que había sido acertadamente declarada "de legalidad cuestionable” por Rego, 2009: 420, y que ha desaparecido de la versión finalmente aprobada. 
Como requisito para la elección del canal, el ejercicio de este derecho se encuentra sometido a petición expresa del interesado. El régimen previsto contiene una sola restricción: el cambio de canal es aplicable a actos sucesivos, no a los trámites ya celebrados; en materia de notificaciones lo establece expresamente la Ley 11/2007, y en las comunicaciones en general debe postularse esa misma conclusión por simple lógica de la mecánica procedimental ${ }^{28}$.

Otra complicación que resulta de este orden de cosas es la eventual convivencia de dos soportes en el expediente administrativo, uno para cada fase de la tramitación, anterior y posterior al ejercicio del derecho a cambiar de medio. En tal caso, una vez terminado el procedimiento, se podría suprimir uno de los soportes (normalmente, el papel), digitalizando los documentos con arreglo al art. 30 LAE.

Para cerrar el análisis relativo a la opción del interesado por otros canales de notificación, y a los solos efectos de ponderar adecuadamente el efecto de su elección por el medio postal, conviene tener presente que, según veremos más adelante, los supuestos de notificación postal infructuosa en materia de tráfico (incluido especialmente el doble intento infructuoso) culminan con la publicación de la notificación en el Tablón Edictal [electrónico] de Sanciones de Tráfico -arts.77 y 78 TALT-, sin que deba procederse a la publicación del acto administrativo en el diario oficial correspondiente como ocurre en el régimen general de las notificaciones administrativas art. 59.5 LRJPAC-. Este factor puede privar de ventaja competitiva a la elección por el medio postal.

Y para completar las reflexiones referentes a la creación de la DEV, a su asignación forzosa, y a su carácter de medio necesario de notificación del acuerdo de incoación del procedimiento, conviene reparar en que la asignación forzosa de la DEV va a suponer una nueva área de negocio para prestadores de servicios de asesoría y gestión administrativa. En efecto, es previsible que estos operadores ofrezcan sus servicios a los titulares de los vehículos (y a sus arrendatarios a largo plazo), a fin de actuar como representantes suyos y recibir las notificaciones que se les dirijan, evitando que se tengan por practicadas al no descargarlas el destinatario. Vaticino que esta externalización de los servicios de recepción de notificaciones administrativas será especialmente intensa en todo el espectro de entidades que tienen contratados los servicios generales de gestoría con empresas especializadas, pues esta misma representación se está produciendo en relación con los medios telemáticos de presentación de declaraciones tributarias.

28 Para mayor claridad, el Real Decreto de desarrollo de la Ley 11/2007 lo establece expresamente así en relación con la Administración del Estado, disponiendo su art. 33 que: "Salvo las excepciones previstas en el artículo anterior, los ciudadanos podrán modificar la manera de comunicarse con los órganos u organismos públicos vinculados o dependientes de la Administración General del Estado, optando por un medio distinto del inicialmente elegido, que comenzará a producir efectos respecto de las comunicaciones que se produzcan a partir del día siguiente a su recepción en el registro del órgano competente”. Será 46 desarrollos reglamentarios de la materia. 


\section{C) Ámbito subjetivo: administraciones públicas que deben cursar las notificaciones de tráfico mediante la DEV}

Una importante novedad derivada de la Ley 18/2009 es que la DEV es única para todas las notificaciones en materia de tráfico que practiquen todas las administraciones públicas. Así resulta del art. 77.1 TALT, que dispone: “Las Administraciones con competencias sancionadoras en materia de tráfico notificarán las denuncias que no se entreguen en el acto y las demás notificaciones a que dé lugar el procedimiento sancionador en la Dirección Electrónica Vial”. Es de notar que esta previsión incide plenamente en las competencias de autoorganización de las diferentes Administraciones públicas, por lo que se sustenta en el título competencial estatal relativo al régimen jurídico básico de las Administraciones públicas.

La previsión atiende la circunstancia de que el vehículo es un elemento móvil que se sitúa sucesivamente bajo la jurisdicción de diferentes Administraciones públicas, lo cual puede suponer un problema a la Administración notificante y el propio interesado. Como explica la Exposición de Motivos de la Ley 18/2009: "En estas circunstancias se crean la Dirección Electrónica Vial (DEV) y el Tablón Edictal de Sanciones de Tráfico, en formato digital. Ambos parten de la realidad que el vehículo supone y que implica su traslado continuo, situándose sin solución de continuidad bajo el ámbito territorial de diferentes Administraciones con competencias sancionadoras. En este sentido, el conductor debe poder contar con un lugar cierto de notificaciones donde todas las Administraciones del tráfico puedan remitirle las diferentes comunicaciones. Asimismo, debe ser suficiente ese lugar para que cualquier conductor pueda conocer si sobre él o su vehículo se ha ejercido o se está ejerciendo la potestad sancionadora en materia de tráfico, sea cual fuere el ámbito territorial donde el hecho se hubiese cometido. Las nuevas tecnologías ayudan sin duda a esta nueva concepción".

No obstante, con arreglo a la Disposición adicional 5 a de la Ley 18/2009, "Las Comunidades Autónomas con competencias ejecutivas en materia de tráfico podrán sustituir las notificaciones en la Dirección Electrónica Vial por notificaciones a través de sus propias plataformas informáticas, para aquellos ciudadanos que opten por las mismas. (...) Las Administraciones Locales pertenecientes a los ámbitos territoriales de las Comunidades Autónomas con competencias en materia de tráfico podrán suscribir convenios de colaboración para efectuar las notificaciones telemáticas a través de las plataformas de notificación y de los Tablones Edictales de la Comunidad Autónoma".

Este orden de cosas hace ver que el legislador prima la disponibilidad del medio electrónico de notificación por encima de cualquier otra consideración. Por ello, de entrada, establece la obligación de todas las Administraciones públicas de notificar mediante la DEV, de forma que quede garantizado el objetivo de eficacia que subyace en todo el texto legal. A partir de esa premisa, se sientan excepciones que no obvian nunca la consecución del objetivo, admitiendo la notificación mediante las plataformas informáticas de las Comunidades Autónomas que ostenten competencias ejecutivas en materia de tráfico. En relación con las entidades locales, resulta en cualquier 
caso anómalo que no se les permita notificar mediante sus propios servicios o plataformas de notificación, sobre todo teniendo presente que el régimen general de las notificaciones electrónicas ha conducido a un big bang de sistemas, servicios y direcciones electrónicas, incluso en el seno de una misma Administración pública, haciendo un flaco favor a la ciudadanía cuando se articulan diferentes formas de notificación y además cuando cada Administración pública puede regular y establecer las propias, sin que exista un punto único de acceso en el que acceder a todas las notificaciones que se le practiquen ${ }^{29}$.

Para concluir, el hecho de que todas las Administraciones públicas -salvo las excepciones reseñadas- deban notificar mediante la DEV supondrá inevitablemente problemas de interoperabilidad que la Ley no declara cómo resolver: por ejemplo, las Administraciones remitentes de notificaciones, ¿podrán enviar el texto en papel, o habrán de hacerlo necesariamente en soporte electrónico? ¿En qué formato habrán de enviar los ficheros? Estas cuestiones deberían solventarse, al menos, con ocasión del desarrollo reglamentario general que anuncia la propia Ley 18/2009.

\section{El Tablón Edictal de Sanciones de Tráfico (TESTRA)}

Como he dicho más arriba, uno de los aspectos que introduce mayor demora en la eficacia de las sanciones de tráfico es la necesidad de publicar las notificaciones administrativas una vez producido el doble intento infructuoso de notificación postal. Semanalmente se publican más de 4.000 páginas de notificaciones de tráfico en los diferentes diarios oficiales ${ }^{30}$, lo que genera un enorme volumen de gestión. Anualmente se publican más de 2.000 de notificaciones, repartidas por diferentes organismos, lo que a su vez disemina las fuentes de publicación complicando el conocimiento efectivo de los actos por parte de la ciudadanía ${ }^{31}$. Para atender esta circunstancia, el art. 78 TALT, en la redacción que le confiere la Ley 18/2009, crea el Tablón Edictal de Sanciones de Tráfico (TESTRA), donde se practicarán de manera centralizada todas las notificaciones que no puedan efectuarse en la DEV o en el domicilio del interesado, sea cual sea la Administración notificadora.

Los tablones de anuncios electrónicos tienen una regulación general en el art. 12 $\mathrm{LAE}$, que los encuadra en el marco de la sede electrónica: esto es, "aquella dirección electrónica disponible para los ciudadanos a través de redes de telecomunicaciones cuya titularidad, gestión y administración corresponde a una Administración Pública, órgano o entidad administrativa en el ejercicio de sus competencias" -art. 10.1 LAE-32. Las sedes electrónicas atienden el propósito de articular un canal de comunicación con

29 Aspecto en el que ya insistí en Gamero, 2005: 196 ss.; y en el que igualmente inciden Valero, 2007: 157 y sigs.; y Martínez, 2009: 549 ss.

30 Estela, Berral y Peñín, 2010.

31 Ibidem.

32 Sobre las sedes electrónicas y los tablones de anuncios electrónicos, véanse Valero, 2009: 284

48 ss.; Martínez, 2009, 477 ss. Rego, 2009: 436 ss.; Martín Delgado, 2009: 106 ss. 
la ciudadanía en condiciones de seguridad, autenticidad, disponibilidad, accesibilidad y responsabilidad. No todo punto de acceso electrónico tiene la condición de sede, sino tan sólo aquéllos que se creen conforme a las características específicas que cada Administración pública determine reglamentariamente -art. 10.3 LAE-. En la Administración del Estado, estas características han sido establecidas en los arts.3 ss. RDLAE, que determina su creación mediante Orden del Ministro correspondiente o Resolución del titular del organismo público. La sede electrónica de la DGT se creó por Resolución de 11 de marzo de $2010^{33}$, siendo única para todo el organismo, y accesible en https://sede. dgt.gob.es En ese punto de acceso electrónico se emplazará sin duda el TESTRA.

La Resolución de 11 de marzo de 2010 únicamente procede a la creación de la sede, pero no incluye contenidos específicos relativos al tablón de edictos. El art. 78.2 TALT establece que la práctica de la notificación en el TESTRA tendrá lugar en los términos que se determinen mediante Orden del Ministro del Interior. Hemos de entender que este desarrollo reglamentario concierne no sólo a los aspectos procedimentales, sino también a los técnicos, concretando las características del sistema. La configuración definitiva del tablón tendrá lugar cuando se apruebe dicho instrumento, si bien resulta posible adelantar alguna de sus características. En este sentido, TESTRA no se circunscribe a la publicación de sanciones, sino que tiene un cometido más amplio: el convertirse "en el tablón de la sede electrónica de la Dirección General de Tráfico (DGT) desde el que se concentran las publicaciones fehacientes de anuncios y edictos tanto en materia sancionadora como en otras áreas como conductores, vehículos o seguridad vial, entre otros. Al igual que en el caso del Boletín Oficial del Estado electrónico, se abre una nueva era en la tramitación de anuncios y edictos en sede electrónica de DGT, sustituyendo la edición impresa”34.

Es importante notar que TESTRA constituye un tablón edictal único para todas las sanciones de tráfico, con independencia de la Administración sancionadora o notificadora, por lo que damos por reproducidas aquí las consideraciones que anteriormente hacíamos sobre esta misma circunstancia en relación con la DEV, pero sin olvidar el valor añadido que en este caso supone el parágrafo 2 de la Disposición adicional quinta de la Ley 18/2009, que dispone: “Las publicaciones en el Tablón Edictal de Sanciones de Tráfico de las Comunidades Autónomas con competencias ejecutivas en materia de tráfico podrán efectuarse a través de sus propios Tablones Edictales. En este caso, los Tablones deberán interoperar entre sí permitiendo al ciudadano, a través de un único acceso, el conocimiento y la comunicación de cualesquiera notificaciones de procedimientos sancionadores que sobre él existan". Esta previsión constituye un magnífico ejemplo de los grandes adelantos que pueden lograrse implantando las tecnologías de la comunicación a la gestión administrativa en Estados intensamente descentralizados como es el caso de España: aunque cada Administración ejerza su propia competencia, ello no supondrá inconveniente alguno para

33 BOE núm.66, de 17 de marzo.

34 Estela, Berral y Peñín, 2010. La aportación de los autores viene avalada por su condición de responsables de la Gerencia de Informática de la DGT. 
la ciudadanía, que dispondrá en todo caso de una fuente integrada de consulta donde verificar la situación de sus expedientes administrativos.

La imagen del TESTRA que se ha difundido en los documentos de trabajo es la siguiente:

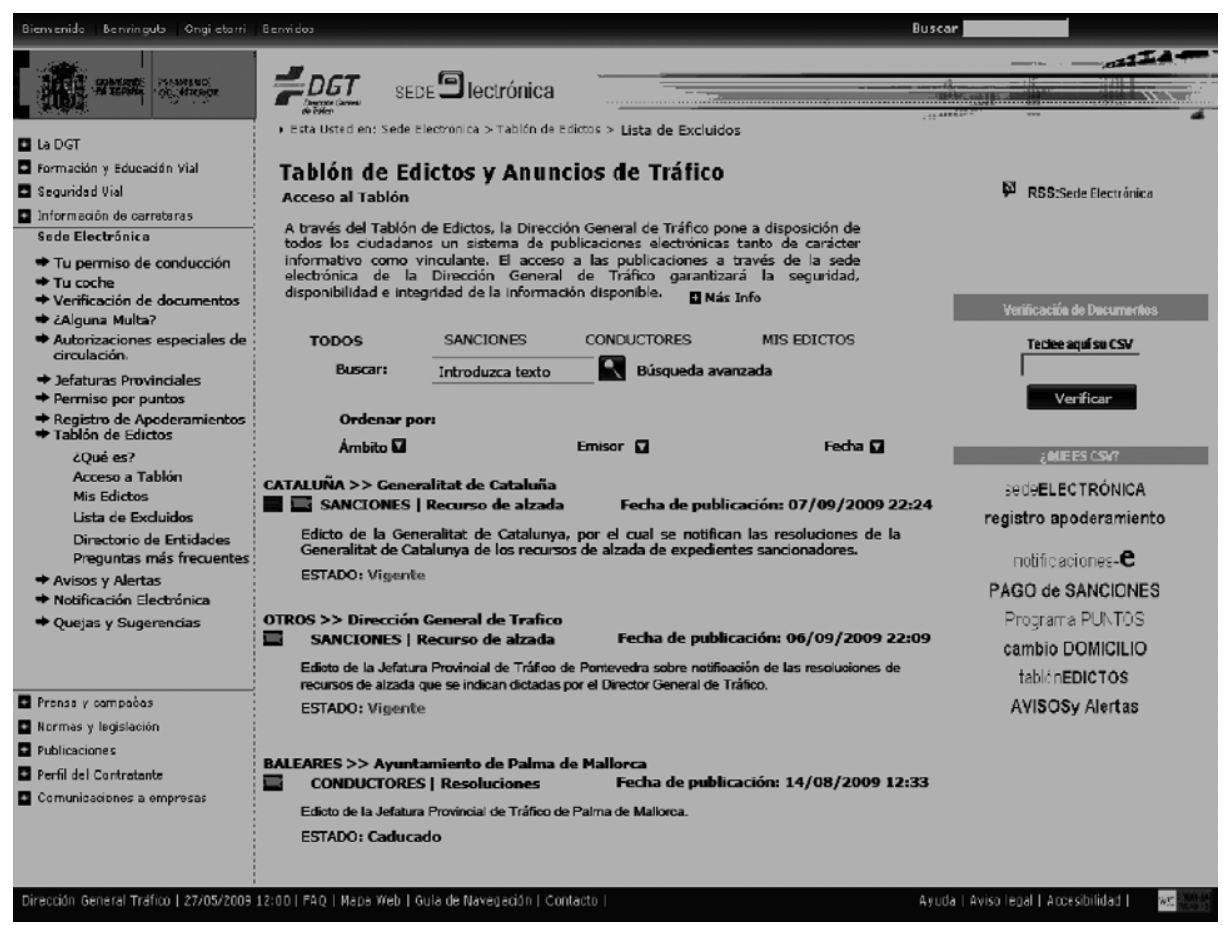

Un importante aspecto a considerar en la publicación electrónica de actos administrativos es la posible afección al régimen de protección de datos ${ }^{35}$. Las características de TESTRA dirigidas a preservar el derecho de protección de datos personales son -entre otras- las siguientes ${ }^{36}$ :

- Se limitan los datos de carácter personal publicados a número de expediente, nombre y apellidos razón social, y NIF/DNI/NIE.

35 Materia que ha sido objeto de diferentes resoluciones de las agencias de protección de datos y para cuyo estudio debe acudirse a Guichot, 2009: 261 ss.; y VV.AA., 2009, en particular la aportación de Valero, 177 ss. Véase además la Recomendación 2/2008, de 25 de abril, sobre publicación de datos personales en boletines y diarios oficiales en Internet, en sitios web institucionales y en otros medios electrónicos y telemáticos.

36 Estela, Berral y Peñín, 2010. 
- Se articula el ejercicio en línea de los derechos ARCO (actualización, rectificación, consulta y oposición), mediante el empleo del DNIe o certificado reconocido.

- Se lleva a cabo un control de caducidad o vigencia de los edictos, con retirada una vez vencidos.

- Se limita la búsqueda por parte de motores externos.

- Se implanta una lista de excluidos, de suscripción voluntaria por los ciudadanos que lo deseen, en cuyo caso las notificaciones en el tablón se practicarán sin incluir más datos que el número de expediente, accediendo las personas interesadas al contenido del tablón mediante certificado electrónico para saber si existe alguna publicación en el tablón.

En cuanto a los aspectos estrictamente procedimentales (en qué momento, y en razón de qué presupuestos de hecho, se procederá a la publicación de la notificación en el tablón de anuncios edictal), la cuestión se abordará más adelante, con ocasión del estudio de los trámites de las notificaciones en materia de tráfico y sus incidencias.

\section{LA PRÁCTICA DE LAS NOTIFICACIONES ELECTRÓNICAS EN MATERIA DE TRÁFICO Y SUS INCIDENCIAS}

Los aspectos más innovadores de las notificaciones electrónicas en materia de tráfico han sido expuestos en los apartados precedentes. El comentario que emprendo a continuación, por el contrario, presenta grandes similitudes con la situación existente en materia de notificaciones electrónicas generales, pues a pesar de regularse la materia en la propia Ley de tráfico, su régimen material es perfectamente análogo al que establece la Ley 11/2007 en relación con las notificaciones electrónicas en general. Las coordenadas generales de esta regulación se contienen en el art. 77. 2 TALT37, que dispone:

2. El sistema de notificación en la Dirección Electrónica Vial permitirá acreditar la fecha y hora en que se produzca la puesta a disposición del denunciado del acto objeto de notificación, así como el acceso a su contenido, momento a partir del cual la notificación se entenderá practicada a todos los efectos legales.

37 Por su parte, el art. 28.2 y 3 LAE dispone:

“2. El sistema de notificación permitirá acreditar la fecha y hora en que se produzca la puesta a disposición del interesado del acto objeto de notificación, así como la de acceso a su contenido, momento a partir del cual la notificación se entenderá practicada a todos los efectos legales.

"3. Cuando, existiendo constancia de la puesta a disposición transcurrieran diez días naturales sin que se acceda a su contenido, se entenderá que la notificación ha sido rechazada con los efectos previstos en el artículo 59.4 de la Ley 30/1992 de Régimen Jurídico y del Procedimiento Administrativo Común y normas concordantes, salvo que de oficio o a instancia del destinatario se compruebe la imposibilidad técnica o material del acceso". 
Si existiendo constancia de la recepción de la notificación en la Dirección Electrónica Vial, transcurrieran diez días naturales sin que se acceda a su contenido, se entenderá que aquélla ha sido rechazada, salvo que de oficio o a instancia del destinatario se compruebe la imposibilidad técnica o material del acceso. El rechazo se hará constar en el expediente sancionador, especificándose las circunstancias del intento de notificación, y se tendrá por efectuado el trámite, continuándose el procedimiento.

Estas previsiones construyen una serie de reglas específicas en relación con las incidencias que pueden presentarse en la práctica de las notificaciones electrónicas. Se trata, por tanto, de determinaciones relativas a la eficacia del acto administrativo notificado. Las estudiamos seguidamente. Como presupuesto del análisis es preciso recordar que la mayoría de formas de notificación se articulan momentos sucesivos claramente diferenciados, cuya secuencia conviene recordar antes de analizar el régimen jurídico de esta materia. Son los siguientes:

1. La entrega al destinatario de un mensaje electrónico, depositado en un servidor (o buzón), que puede consistir en una dirección electrónica habilitada, o en una dirección electrónica con acuse de recibo de lectura. Es una práctica muy extendida que el mensaje remitido a ese buzón no contenga directamente el acto notificado, sino que éste se remita en un fichero ligado al mensaje de correo electrónico, generalmente en formato pdf.

2. La conexión del destinatario al servicio de mensajería electrónica o plataforma de notificación. En este momento puede visualizar una lista de mensajes pendientes de leer, pero todavía no ha accedido al contenido de ninguno de ellos.

3. La recepción por el destinatario de la notificación, mediante la descarga del mensaje en su equipo terminal, junto con el fichero ligado en el que se contiene verdaderamente el acto notificado.

4. La lectura por parte del destinatario del fichero adjunto, ejecutando el archivo con su programa informático correspondiente.

\section{Momento en que debe entenderse practicada la notificación}

Conforme al art. 77.2 TALT, la notificación se entenderá practicada en el momento en que se produzca el acceso del interesado a su contenido. No es sencillo determinar el sentido de este precepto. Si lo interpretamos en sentido literal, la notificación solo sería válida cuando quede probado que el interesado ha llegado a acceder materialmente al contenido de la notificación misma. Si atendemos a la secuencia anteriormente descrita, cuando la notificación se contiene en un fichero adjunto a un mensaje electrónico, esto supone que debemos disponer de algún medio probatorio del momento en el que el destinatario abrió el ese fichero adjunto al mensaje electrónico. Esta consecuencia resulta sencillamente absurda, y supondría una inexplicable diferencia respecto del régimen de las notificaciones postales, en las que basta la 
entrega al destinatario o persona habilitada para que se entienda practicado el trámite, sin necesidad de que el cartero deje constancia de que el destinatario abrió el sobre para conocer el contenido de la notificación.

Por esta razón entiendo que, cuando la notificación se articula en los términos expuestos, debe entenderse practicada cuando el destinatario se descargue en un equipo terminal el mensaje electrónico con el que se procede a la notificación (es decir, el "tercer momento" de la relación anterior), ya sea incorporándose directamente a dicho mensaje los contenidos propios de las notificaciones administrativas, ya sirviendo tan sólo para adjuntar un fichero en el que se contiene realmente la notificación ${ }^{38}$. Esta no es la opinión doctrinal mayoritaria: en general, se entiende que es preciso que el destinatario acceda verdaderamente al contenido de la notificación, aunque existen diferentes variantes de esta postura ${ }^{39}$.

\section{Rechazo tácito, permanencia de la notificación a disposición del destinatario y supresión del segundo intento de notificación}

El orden de cosas dispuesto por el art. 77.2 TALT dejaría en manos del interesado el momento en que se perfecciona la notificación, de tal manera que le bastaría con no consultar el contenido de los mensajes para evitar que se produzca la notificación; por ello, resulta preciso definir una regla supletoria temporal cuya aplicación venga determinada por circunstancias objetivas al margen de la actitud del interesado ${ }^{40}$. Es lo que busca el art. 77.2 parágrafo 2 TALT, con arreglo al cual, el rechazo -tácito- de la notificación electrónica se produce cuando el mensaje se encuentra disponible por espacio de diez días en el buzón del destinatario sin que éste acceda a su contenido. Este régimen constituye una destacable especialidad de este medio de notificación, que excepciona el protocolo aplicable al resto de medios admitidos por la legislación del procedimiento administrativo común, y que he criticado duramente con anterioridad en términos que reitero ahora ${ }^{41}$. Este cambio entraña una verdadera presunción iuris et e iure, que además supone una tergiversación de la realidad material, pues evidentemente no es lo mismo un rechazo (término que presupone la actitud deliberada de no ser notificado), que una simple omisión de acceso (que puede ser involuntaria y deberse a una mera omisión, descuido o imposibilidad); por consiguiente, habría sido preferible que en este caso la Ley afirmara sencillamente que la notificación

38 En la misma posición, Álamo, 2007: 128; y Martínez, 2009: 553.

39 Por ejemplo, Valero, 2007: 171 ss., en relación con el régimen general de las notificaciones electrónicas establecido en la Ley 11/2007, parece dar a entender que comparte la misma opinión que defiendo en el texto, aunque prefiere que una reforma legal declare que se entenderá practicada la notificación en el momento en que el destinatario acceda al buzón o dirección electrónica (el momento 2 de la secuencia indicada) aunque no llegue siguiera a descargarse el mensaje. Por su parte, Martín Delgado, $2009: 98$ ss., es categórico al sostener la exigencia de que se demuestre que el destinatario accede materialmente al contenido de la notificación, extendiéndose en pormenorizar sus razones. También Rego, 2009: 403, parece compartir esta última posición.

40 Vid. Valero, 2007: 173.

41 Vid. Gamero, 2002: 521 ss.; y 2005: 221 y sigs. 
se entendería practicada a todos los efectos, produciéndose una notificación tácita mejor que un rechazo tácito de la notificación. Las críticas a este régimen legal son unánimes ${ }^{42}$.

En relación con el plazo de permanencia de la notificación en el buzón del destinatario, se plantea Valero la hipótesis de que la Administración pretenda retirarla una vez vencido dicho plazo perentorio arguyendo razones técnicas, como por ejemplo la limitación del espacio disponible; en su opinión, que suscribo plenamente, el mensaje debería permanecer en el servidor un período prudencial, toda vez que la falta de consulta puede deberse a un mero descuido del usuario y no a su intención deliberada, por lo que sugiere la permanencia del mensaje en tanto se encuentren abiertos los plazos de recurso contra el acto notificado ${ }^{43}$. En la información disponible acerca de las notificaciones en materia de tráfico ${ }^{44}$, se conoce la intención de mantener en el TESTRA las notificaciones edictales ya caducadas, pero no se tienen noticias análogas en relación con la permanencia de la notificación en la DEV.

En conexión con lo anterior, el propio precepto suprime el segundo intento de notificación, que de acuerdo con las reglas generales debería tener lugar en el espacio de tres días y a distinta hora. Ambas particularidades de la notificación por correo electrónico no dejan de tener su lógica: el segundo intento encuentra su razón de ser en los medios de notificación de carácter inmediato, que no permiten el depósito del mensaje en algún lugar de donde el destinatario o su representante puedan retirarlo con mayor disponibilidad horaria dejando constancia del hecho.

\section{Imposibilidad técnica o material de acceso al contenido}

Otro aspecto nada pacífico del régimen de las notificaciones electrónicas es el inciso final del art. 28.3 LAE, equivalente al primer inciso del segundo parágrafo del art. 77.2 TALT, según el cual "Si existiendo constancia de la recepción de la notificación en la DEV transcurrieran diez días naturales sin que se acceda a su contenido, se entenderá que la notificación ha sido rechazada salvo que de oficio o a instancia del destinatario se compruebe la imposibilidad técnica o material del acceso".

Ante todo, es preciso acotar el alcance de la imposibilidad, que debe ser exclusivamente la que resulte imputable al proveedor del servicio de mensajería electrónica, y nunca a otro tipo de causas (enfermedad del destinatario, avería de su equipo terminal, o cualquier otra) que permitan al destinatario condicionar por sí mismo la validez de la notificación con gran facilidad: siendo requisito sine qua non para el empleo de este medio de notificación el previo consentimiento del destinatario, parece justo

42 Que son especialmente prolijas en Martín Delgado, 2009: 109 ss.; vid. igualmente Rego, 2009: 433; Bauzá, 2002: 190 y sigs.; y VValero, 2007: 153.

$54 \quad \begin{array}{lll}53 & \text { Vid. Valero, 2007: } 134 \text { ss. } \\ & 44 & \text { Estela, Berral y Peñín, } 2010 .\end{array}$ 
que recaiga sobre él toda incidencia relativa a su esfera personal y no al mal funcionamiento del servidor, porque de otro modo la eficacia del acto queda excesivamente condicionada por avatares que no le son imputables a la Administración en modo alguno ${ }^{45}$. Entiendo, por tanto, que la expresión “imposibilidad técnica 0 material” no comprende toda situación en que haya sido materialmente imposible el acceso al buzón, sino que se contrae a las circunstancias en las que el acceso no ha podido tener lugar por razones materiales, esto es, imputables a circunstancias estrictamente objetivas y específicamente relacionadas con el servidor de correo electrónico o con el prestador de servicios de certificación que interviene en el proceso de notificación.

Por otra parte, el precepto no establece las consecuencias que derivarían de esta comprobación, de modo que no sabemos lo que debe ocurrir cuando se demuestre la imposibilidad técnica o material del acceso: está claro que no puede entenderse el supuesto como rechazo de la notificación, pero no se determina si la Administración deberá proceder a un segundo intento por el mismo medio o por otro diferente, o bien puede interpretarse esta incidencia como una notificación infructuosa y procederse a la notificación sustitutiva mediante edictos en el TESTRA. En el caso de que se opte por repetir el intento de notificación, queda también sin respuesta legal el modo de efectuar el cómputo del plazo de depósito, pues la Ley no define si se reanudará el plazo en el punto en que se interrumpió la disponibilidad del mensaje -culminando lo que reste hasta el total de diez días-, o bien se concederá de nuevo el plazo íntegro - diez días completos- a efectos de cómputo de un eventual rechazo tácito posterior. Por añadidura, cuando la Administración no reciba acuse de recibo de la notificación en el plazo de diez días, podrá desconocer si ello se debe a la desidia del destinatario (que simplemente no descargó su correo), o a la existencia de problemas en el servidor, por lo que no sabrá a ciencia cierta si debe entender presuntamente rechazada la notificación o no ${ }^{46}$.

45 Por el contrario, para Valero, 2007: 177 y sigs., cuando la causa que impide al acceso se sitúa en el ámbito del destinatario sería preciso distinguir entre impedimentos objetivos y subjetivos. A juicio del autor, los primeros, relativos a circunstancias técnicas, no podrían bloquear la eficacia del acto cuando resulten imputables a un tercero (por ejemplo, fallos en el servidor que impiden acceder al buzón); y por el contrario, sí podrían determinar el carácter infructuoso de la notificación (sin conducir a su rechazo tácito) cuando la imposibilidad en el acceso viniera referida a los medios que permanecen bajo el control del interesado y éste hubiera demostrado la diligencia debida podría considerarse la existencia de una justificación suficiente. $Y$ en cuanto a las circunstancias subjetivas, esto es, atinentes a circunstancias personales del destinatario, opina el autor que podría considerarse la existencia de una justificación suficiente cuando la entidad del problema sea tal que, aún empleando toda la diligencia debida, no pudiera conectarse a su dirección electrónica para recibir la notificación.

En mi opinión, esta construcción es excesivamente voluntarista y no casa bien con la práctica seguida en el resto de medios de notificación. Por ejemplo, en el caso de las notificaciones postales, de ser infructuoso el segundo intento se procede sin mayor escrúpulo a la publicación sustitutiva del acto, siendo indiferente que la ausencia del domicilio viniera motivada por el disfrute de vacaciones o por un ingreso hospitalario.

No obstante, la posición de Valero aparece segundada por Martín Delgado, 2009: 111; y por Martínez, 2009: 556 y sigs.

46 No obstante, en el concreto caso de la Administración del Estado, la Orden PRE/1551/2003 impone al prestador del servicio de dirección electrónica única que certifique puntualmente cualquier fallo téc- 
Se ha defendido por Martín Delgado que la principal consecuencia de la imposibilidad de acceso se encuentra en el ámbito del sistema de recursos ${ }^{47}$. En efecto, como sostiene el autor, "la imposibilidad de acceso convierte la presunta notificación rechazada en algo intermedio entre la notificación practicada y la notificación infructuosa" ${ }^{48}$. Normalmente, el destinatario averiguará tardíamente que ha sido objeto de una notificación a la que no ha podido acceder por imposibilidad técnica o material. En ese momento, lo advertirá a la Administración actuante para que se subsane el vicio, o bien interpondrá el recurso procedente contra el acto notificado: este recurso no podrá inadmitirse por extemporáneo si en el momento de su presentación el interesado demuestra la imposibilidad técnica o material del acceso. Por último, como señala el propio autor, si el acto administrativo era favorable, la imposibilidad técnica del acceso resultó imputable exclusivamente a la Administración y el destinatario demostró la diligencia debida en intentar ser notificado, caso de soportar daños patrimoniales como consecuencia de todo ello, podrá presentar una reclamación de responsabilidad extracontractual ${ }^{49}$.

\section{Intento documentado de notificación: caducidad del procedimiento y prescripción}

Otra cuestión a dilucidar en este asunto es el momento en que puede considerarse intentada la notificación a fin de impedir que se produzca el caducidad del procedimiento o de que continúe transcurriendo el plazo de prescripción de la infracción. En mi opinión, conforme al art. 58.4 LRJPAC podría entenderse que, con la puesta a disposición del mensaje en el buzón del destinatario, se daría por satisfecho el requisito del intento de notificación en plazo a efectos de impedir la producción de un acto presunto estimatorio, cuando fuera el caso $^{50}$. De lo que se trata es de probar que el interesado está en disposición de recibir la notificación, o dicho de otro modo, que el momento exacto de recepción de la notificación ya no depende de una actividad de la Administración (su puesta a disposición), sino de una actividad del destinatario: proceder a la conexión telemática y conocer el contenido de la notificación. Esto concuerda con la doctrina contenida en la STS de 17/11/03, rec.128/2002, en cuya virtud, para entender concluso un procedimiento administrativo dentro del correspondiente plazo máximo, basta con realizar un intento documentado de notificación por cualquier medio legalmente admisible según los términos del art. 59 LRJPAC, aunque finalmente dicho intento se revele infructuoso ${ }^{51}$.

nico que haya impedido el acceso al servidor, lo que elimina este problema. Distinto puede ser el régimen instaurado por otras Administraciones públicas en virtud de su capacidad reglamentaria en la materia.

47 Vid. Martín Delgado, 2009: 114.

48 Op.loc.ult.cit., pág.112.

49 Op.loc.ult.cit., pág.114

50 Es también la opinión de Valero, 2007: 154.

51 La doctrina legal fijada por la Sentencia, que se dicta en resolución de un recurso de casación en interés de Ley, es la siguiente: “Que el inciso intento de notificación debidamente acreditado que emplea el artículo 58.4 de la Ley 30/1992, de 26 de noviembre, de Régimen Jurídico de las Administraciones públi- 
Podría estorbar a esta interpretación la puntualización que efectúa Martín Delgado ${ }^{52}$, para quien el inciso "así como el acceso a su contenido, momento a partir del cual la notificación se entenderá practicada a todos los efectos legales" del art. 28.2 LAE -idéntico en este sentido al art. 77.2 TALT-, supondría negar la aptitud de un intento que no llega a culminar en un acceso efectivo del interesado al contenido de la notificación. Por su parte, en opinión de Palomar, la circunstancia que debe entenderse apta para considerar realizado un intento de notificación e impedir que se produzca el silencio administrativo es cuando el interesado ha señalado el electrónico como medio preferente de notificación, y ésta permanece por diez días a su disposición sin que acceda al contenido53.

En mi opinión, por el contrario, cabe perfectamente distinguir entre el intento de notificación y la práctica efectiva de la notificación: a mi juicio, el art. 28.2 LAE y el 77.2 TALT estarían haciendo referencia a esta última, sin pronunciarse en ningún momento acerca de cuándo puede entenderse producido un intento de notificación. La mención a todos los efectos legales debe encontrarse referida a todos los efectos ligados a la eficacia del acto: el inicio de su ejecutividad, el del plazo de impugnación, etc.

\section{Supuestos que conducen a la publicación de la notificación en el TESTRA}

La publicación de los actos administrativos está prevista con carácter general en el Derecho administrativo con tres configuraciones diferentes, según sea supletoria, sustitutoria o complementaria de la notificación administrativa ${ }^{54}$. Los arts.77.3 y 78.1 TALT introducen algunas particularidades en esta materia, concretando los diferentes supuestos en que se procederá a la publicación edictal de las notificaciones de tráfico en el TESTRA. Con arreglo a sus previsiones, los supuestos que dan lugar a la publicación de las notificaciones de actos administrativos en el TESTRA son los siguientes:

1. Cuando se inicien los trámites de notificación por vía postal y el resultado haya sido infructoso tras el doble intento documentado de notificación -art. 77.3

cas y del Procedimiento Administrativo Común, se refiere al intento de notificación personal por cualquier procedimiento que cumpla con las exigencias legales contempladas en el artículo 59.1 de la Ley 30/1992, pero que resulte infructuoso por cualquier circunstancia y que quede debidamente acreditado. De esta manera, bastará para entender concluso un procedimiento administrativo dentro del plazo máximo que la ley le asigne, en aplicación del referido artículo 58.4 de la Ley 30/1992, el intento de notificación por cualquier medio legalmente admisible según los términos del artículo 59 de la Ley 30/1992, y que se practique con todas las garantías legales aunque resulte frustrado finalmente, y siempre que quede debida constancia del mismo en el expediente.

En relación con la práctica de la notificación por medio de correo certificado con acuse de recibo, el intento de notificación queda culminado, a los efectos del artículo 58.4 de la Ley 30/1992, en el momento en que la Administración reciba la devolución del envío, por no haberse logrado practicar la notificación, siempre que quede constancia de ello en el expediente".

52 Vid. Martín Delgado, 2009: 105 ss.

53 Vid. Palomar, 2007: 161 ss.

54 Para abundar en esta clasificación véase Gamero y Fernández Ramos, 2009: 428 ss. 
TALT-: en este caso, en lugar de procederse a la publicación de edictos en el tablón de anuncios del municipio donde el destinatario tuviera su último domicilio conocido y en el diario oficial correspondiente, como sucede en el régimen general previsto por la Ley 30/1992, se procederá a la publicación en el TESTRA. Se produce en este caso, por consiguiente, una importante excepción al Derecho común del procedimiento administrativo.

2. Cuando se inicien los trámites de notificación por vía postal y el destinatario fuere desconocido en esa dirección -art. 77.3 TALT-: en este caso no se procede a la práctica de un segundo intento de notificación, sino que se publica directamente la notificación en el TESTRA.

3. Las notificaciones que no puedan efectuarse en la DEV o en el domicilio indicado por el interesado se practicarán igualmente en el TESTRA -art. 78.1 TALT-. Esta previsión se presenta como una cláusula de cierre ante cualquier incidencia que se produzca con ocasión de las notificaciones, ya sean electrónicas o postales, pero se debe entender en sentido restrictivo. En particular, resultarían inadmisibles causas estrictamente imputables a la esfera organizativa de la Administración (colapso o interrupción en el funcionamiento de la DEV, por ejemplo), y únicamente daría cobertura a causas estrictamente imputables al interesado.

Para concluir, el art. 78.1 TALT también contiene una importante determinación en relación con el régimen jurídico de las notificaciones realizadas mediante el TESTRA: “Transcurrido el período de veinte días naturales desde que la notificación se hubiese publicado en el TESTRA se entenderá que ésta ha sido practicada, dándose por cumplido dicho trámite y continuándose con el procedimiento". Se trata de una clara asimilación de la notificación en el tablón electrónico a la notificación en la dirección electrónica, dando lugar a un supuesto de rechazo tácito ope legis. Tuve ocasión de comentar anteriormente las críticas que suscita ese orden de cosas en materia de notificaciones electrónicas, críticas que ahora hay que hacer extensivas al régimen de la notificación edictal en el TESTRA.

\section{REFERENCIAS BIBLIOGRÁFICAS Y DOCUMENTALES}

Álamo González, N. (2007), “La utilización de las nuevas tecnologías en las relaciones entre las Administraciones públicas y los ciudadanos (en particular, registros telemáticos y notificaciones telemáticas)", REDA, n. ${ }^{\circ} 133$.

Baño León, J.M. (1991), Límites constitucionales a la potestad reglamentaria, Madrid: Civitas. Rebollo Puig, M. (1993), "Juridicidad, legalidad y reserva de ley como límites a la potestad reglamentaria del Gobierno", Revista de Administración Públi$\mathrm{ca}, \mathrm{n} .^{\circ} 125$.

Bauzá Martorell, F.J. (2002), Procedimiento administrativo electrónico. Granada: Comares.

58 Barriuso Ruiz, C. (2007), Administración electrónica. Madrid: Dykinson. 
Bernardí Gil, X. (2005), “Derecho público y Administración electrónica: una visión panorámica”. Nuevas Políticas Públicas, n. ${ }^{\circ} 1$.

Beladíez Rojo. M. (2000), “La vinculación de la Administración al Derecho”, Revista de Administración Pública, n. ${ }^{\circ} 153$.

Bobbio, N. (1960): Teorria dell'ordinamento giuridico. Torino: Giappichelli.

Cotino Hueso, L. (2004): "Derechos del ciudadano administrado e igualdad ante la implantación de la Administración electrónica”, RVAP, n. ${ }^{\circ}$ 68,

Davara Rodríguez, M.A. (2010), Acceso electrónico de los ciudadanos a los Servicios públicos. Madrid: El Consultor de los Ayuntamientos y Juzgados.

Dávila Muro, J. (2001), "La notificación digital hacia los ciudadanos: características y posibles modelos", Seguridad en Informática y Comunicaciones, n. ${ }^{\circ} 45$.

Díez-Picazo, L.M. (1990): La derogación de las leyes. Madrid: Civitas.

Estela Gutiérrez, J.; Berral López, A.; y Peñín Ramírez, F, “TESTRA. Tablón Edictal de Sanciones de Tráfico”, comunicación presentada a Tecnimap 2010, Zaragoza, 6-9 de abril de 2010.

Gamero Casado, E. (2001), Los medios de notificación en el procedimiento administrativo común. Sevilla: Instituto Andaluz de Administración Pública.

Gamero Casado, E. (2002), “La notificación por correo electrónico tras la Ley 24/2001, de 27 de diciembre", Revista Española de Derecho Administrativo, n. ${ }^{\circ} 116$.

Gamero Casado, E. (2005), Notificaciones telemáticas. Y otros medios de notificación administrativa en el procedimiento administrativo común. Barcelona: Bosch.

Gamero Casado, E. (2010), "Comunicaciones y notificaciones electrónicas", Cuadrenos de Derecho Local, n. 22.

Gamero Casado, E. y Fernández Ramos, S. (2009 [2003]), Manual básico de Derecho administrativo. Madrid: Tecnos.

Gamero Casado, E. y Valero Torrijos, J. (coords.) (2009 [2008]), La Ley de administración electrónica. Comentario sistemático a la Ley 11/2007, de 22 de junio, de acceso electrónico de los ciudadanos a los Servicios Públicos, Aranzadi-Thomson-Reuters. Cizur Menor (Navarra): Aranzadi.

Gavazzi, G. (1959): Delle antinomie. Torino: Giappichelli.

Gómez Puente, M. (2007), “La Administración electrónica”, en La autorización administrativa. La Administración electrónica. La enseñanza del Derecho administrativo hoy. Cizur Menor (Navarra): Aranzadi.

Guichot Reina, E. (2009), Publicidad y privacidad de la información administrativa. Cizur Menor (Navarra), Civitas-Thomson-Reuters.

Martín Delgado, I. (2005), "Las notificaciones administrativas telemáticas", en Punzón Moraleda, J. (coord.), Administraciones públicas y nuevas tecnologías. Valladolid: Lex Nova.

Martín Delgado, I. (2009b), “Identificación y autenticación de los ciudadanos”, en Gamero Casado, E. y Valero Torrijos, J. (coords.) (2009 [2008]), La Ley de administración electrónica. Comentario sistemático a la Ley 11/2007, de 22 de junio, de acceso electrónico de los ciudadanos a los Servicios Públicos, Aranzadi-Thomson-Reuters. Cizur Menor (Navarra): Aranzadi.

Martínez Gutiérrez, R. (2009), Administración pública electrónica. Cizur Menor (Navarra): Civitas-Thomson-Reuters. 
Mondugno, F. (1978), “Norme singolari, speciali, eccezionali”, en Enciclopedia del diritto. Milano: Giuffrè.

Palomar Olmeda, A. (2007), La actividad administrativa efectuada por medios electrónicos. Cizur Menor (Navarra): Aranzadi.

Santamaría Pastor, J.A. (1988), Fundamentos de Derecho administrativo. Madrid: Ceura.

Valero Torrijos, J. (2009), “Acceso a los servicios y a la información por medios electrónicos", en Gamero Casado, E. y Valero Torrijos, J. (coords.) (2009 [2008]), La Ley de administración electrónica. Comentario sistemático a la Ley 11/2007, de 22 de junio, de acceso electrónico de los ciudadanos a los Servicios Públicos, AranzadiThomson-Reuters. Cizur Menor (Navarra): Aranzadi.

Valero Torrijos, J. (2007 [2004]), El régimen jurídico de la e-Administración. Granada: Comares.

VV.AA. (2009), La protección de datos en la administración electrónica. Cizur Menor (Navarra): Thomson-Reuters-Aranzadi.

Recibido: 23 de mayo de 2010

Aceptado: 8 de junio de 2010 